\title{
Silver Nanoparticles Confined in SBA-15 Mesoporous Silica and the Application as a Sensor for Detecting Hydrogen Peroxide
}

\author{
Dong-Hai Lin, Yan-Xia Jiang, Ying Wang, and Shi-Gang Sun \\ State Key Laboratory of Physical Chemistry of Solid Surfaces, Department of Chemistry, \\ College of Chemistry and Chemical Engineering, Xiamen University, Xiamen 361005, China \\ Correspondence should be addressed to Yan-Xia Jiang, yxjiang@xmu.edu.cn
}

Received 12 September 2007; Revised 31 January 2008; Accepted 24 March 2008

Recommended by Michael Wong

\begin{abstract}
Silver nanoparticles within the pore channels of selectively grafted mesoporous silica SBA-15 were synthesized. Silanols on the external surface of as-SBA-15 were first capped by $-\mathrm{Si}\left(\mathrm{CH}_{3}\right)_{3}$ groups. After removal of the template of capped SBA-15 by calcination, silanols on the internal surface of SBA-15 were modified by 3-aminopropyltrimethoxysilane (APTMS), and then formaldehyde was grafted by amino groups of APTMS, and further $\left.\mathrm{Ag}\left(\mathrm{NH}_{3}\right)_{2} \mathrm{NO}_{3} \mathrm{SBA}-15\right)$. High-resolution transmission electron microscopy (HRTEM), X-ray diffraction (XRD), Fourier transformation infrared spectroscopy (FTIR), nitrogen adsorption/desorption isotherms, and UV-vis spectra confirm that the silver nanoparticles have been confined inside the channels of SBA-15. In addition, the Ag- ${ }^{\mathrm{m}} \mathrm{SBA}-15$ modified electrode $\left(\mathrm{Ag}-{ }^{\mathrm{m}} \mathrm{SBA}-15 / \mathrm{GC}\right)$ exhibited an excellent electrocatalytic activity toward the reduction of hydrogen peroxide $\left(\mathrm{H}_{2} \mathrm{O}_{2}\right)$. The proposed $\mathrm{H}_{2} \mathrm{O}_{2}$ sensor exhibits a linear range of $48.5 \mu \mathrm{M}-0.97 \mathrm{M}$ with a detection limit of $12 \mu \mathrm{M}(\mathrm{S} / \mathrm{N}=3)$ and analytical time of 10 seconds per sample.
\end{abstract}

Copyright (C) 2008 Dong-Hai Lin et al. This is an open access article distributed under the Creative Commons Attribution License, which permits unrestricted use, distribution, and reproduction in any medium, provided the original work is properly cited.

\section{INTRODUCTION}

Recently, the discovery of mesoporous silicas, such as M41s [1] and SBA-15 [2], has stimulated intensive studies of "hostguest" chemistry inside the channels of mesoporous silicas [3-6], which have potential applications in catalysis, selective adsorbents, medical [7], sensors $[8,9]$, and nanomaterials fabrications. Thanks to their uniform mesostructures, high surface areas, and tunable pore sizes [2], these ordered mesoporous silicas have been used as the promising templates to control the shape and size of metal nanoparticles [10-16]. Many published works gave the relation between nanoparticles confined in various molecular sieves and their properties [17-19]. Moreover, the surface of these ordered mesoporous silicas are also modified for many potential applications. For modifying the mesoporous materials through covalent linkage between functional groups and silica framework, two major methods, grafting (post synthesis) and cocondensation (direct incorporation), have been traditionally explored [20]. Grafting is one of the modification methods for presynthesized mesoporous silica, in which the organic functional groups can be introduced by direct reaction of organosilanes to silica surface. It is up to the application of thus formed materials, other functionalities can be fixed to the previously introduced functional groups including amino, thiol, and alkyl groups through covalent bonding and/or molecular recognition [20-23]. The distribution and concentration of functional groups are influenced by reactivity of the organosilane and their accessibility to surface silanols, which are limited by diffusion and steric factors. Chao et al. $[6,11]$ prepared SBA-15 functionalized with $\left(\mathrm{CH}_{3} \mathrm{O}\right)_{3} \mathrm{Si}\left(\mathrm{CH}_{2}\right)_{3} \mathrm{~N}\left(\mathrm{CH}_{3}\right)_{3} \mathrm{Cl}$ (TPTAC) and further synthesized metal nanoparticles by anion exchange between grafted SBA-15 and metal precursors inside the channels as well as upon reduction of precursors. The amount of metal loading as well as the morphology of metal in host SBA-15 can be rationally controlled through repeating ionexchange/reduction cycles in the TPTAC-SBA-15 silica host. They used the same method to prepare Au nanoparticles and found that the size and morphology of Au nanoparticles in mesoporous SBA-15 are controllable by the preparation methods. 
However, above-mentioned grafting methods basically allow introduction of functionalization at both intrapore and extrapore media, which led the nanoparticles form at both surfaces. Therefore, large metal particles aggregate would form on the external surface of the host materials. To overcome this disadvantage, Shi et al. [4] synthesized Pt nanoclusters within the pore channels of selectively modified mesoporous silica SBA- 15 by a new in situ reduction process. The silanols on the external surface of SBA-15 were capped with $-\mathrm{Si}\left(\mathrm{CH}_{3}\right)_{3}$ groups, thus effectively avoiding the formation of large particles outside the channels. On the other hand, the inner surface of the channel was functionalized with highly reducing $\mathrm{Si}-\mathrm{H}$ bonds. Pt nanoclusters were formed inside the channels of SBA- 15 from $\mathrm{H}_{2} \mathrm{PtCl}_{6}$ by in situ reduction with $\mathrm{Si}-\mathrm{H}$ bonds. Recently, Sun et al. [3] have developed a novel in situ autoreduction route to synthesize monodispersed silver nanoparticles inside the channels of SBA-15. It was demonstrated for the first time by the ${ }^{13} \mathrm{C} C \mathrm{CP} / \mathrm{MAS}$ NMR spectroscopy that amino groups of aminopropyltriethoxyl silane (APTS) modified mesoporous silica can be used to anchor formaldehyde to form $\mathrm{NHCH}_{2} \mathrm{OH}$ species, on which $\mathrm{Ag}\left(\mathrm{NH}_{3}\right)_{2} \mathrm{NO}_{3}$ could be in situ reduced. The silver nanoparticles confined inside the channels of SBA-15 resulted in an unusual thermal stability.

Nanoparticles confined in SBA-15 silica possess high catalytic activity and stability thanks to the stabilizer-free and confined. Jiang et al. [24] found that the Pt nanoparticles confined in SBA-15 exhibit a high electrocatalytic activity toward the oxidation of carbon monoxide (CO) and methanol, and the linearly adsorbed CO species is the only intermediate derived from dissociative adsorption of methanol, which is more readily oxidized to form $\mathrm{CO}_{2}$ in the aid of the active oxide in SBA- 15 .

Rapid, accurate, reliable, and reagentless determination of hydrogen peroxide $\left(\mathrm{H}_{2} \mathrm{O}_{2}\right)$ is of great importance in food, clinical, pharmaceutical, industrial, and environmental analysis. Many analytical techniques have been reported for determination of hydrogen peroxide, for example, chemiluminescence [25], titrimetry [26], and spectrophotometry $[25,27]$. Electrochemistry is an inexpensive and effective way to examine the reactions of many substances $[27,28]$. Amperometric sensors are especially attractive because of their simplicity and high sensitivity. By now horseradish peroxidase (HRP), one of the most studied members of the family of heme enzymes, was shown to catalyze the reaction of nonmediated cathodic reduction of $\mathrm{H}_{2} \mathrm{O}_{2}$ resulting from direct electron transfer from the electrode to the heme containing active site of HRP when immobilized at the electrode surface $[29,30]$. Nevertheless, these systems were found to be too complex and the linear range for $\mathrm{H}_{2} \mathrm{O}_{2}$ detection is narrow.

In this paper, the stabilizer-free and confined silver nanoparticles inside the channels of selectively grafted mesoporous silica SBA-15 by an in situ reduction process were synthesized (see Scheme 1). The catalytic activity of silver nanoparticles confined in the mesoporous silica SBA15 to the reduction of hydrogen peroxide $\left(\mathrm{H}_{2} \mathrm{O}_{2}\right)$ was studied for sensing application. The Ag- ${ }^{\mathrm{m}} \mathrm{SBA}-15 / \mathrm{GC}$ modified electrode, thus allowed highly sensitive amperometric detection of $\mathrm{H}_{2} \mathrm{O}_{2}$, low applied potential, and a broad linear relationship with the concentration of $\mathrm{H}_{2} \mathrm{O}_{2}$ over a wide range of $4.8 \times 10^{-5}-9.7 \times 10^{-1} \mathrm{M}$. The new application of the stabilizer-free silver nanoparticles confined inside the channel of SBA-15 mesoporous silica, an attractive electrocatalytic nanomaterial for preparation of an amperometric sensor is proposed.

\section{EXPERIMENTAL}

\subsection{Synthesis of $\mathrm{Ag}^{\mathrm{m}}{ }^{\mathrm{S}} \mathrm{SBA}-15$}

As illustrate by Scheme 1, mesoporous silica SBA-15 was synthesized following the published procedure [2] using the triblock copolymer Pluronic P123 as a template in acid conditions. Typically, a $6.4 \mathrm{~g}$ Pluronic P123 template was dissolved with stirring in a solution of $250 \mathrm{~mL}$ of $2 \mathrm{M} \mathrm{HCl}$ at $313 \mathrm{~K}$, and $13.6 \mathrm{~g}$ of tetraethyl orthosilicate (TEOS) was then added. The resulting mixture was stirred at $313 \mathrm{~K}$ for 20 hours, and then aged at $373 \mathrm{~K}$ for 24 hours under static condition. The recovered solid was extensively washed with deionized water and drying at $353 \mathrm{~K}$ for 12 hours yielded as-SBA-15. To get calcinated SBA-15 (cal-SBA15), the surfactant template of as-SBA- 15 was removed by calcination in air at $823 \mathrm{~K}$ for 6 hours.

Ag- ${ }^{\mathrm{m}} \mathrm{SBA}-15$ was prepared according to the literature procedure [3]. $2.0 \mathrm{~g}$ as-SBA-15 was dispersed in $150 \mathrm{~mL}$ dry toluene under flowing $\mathrm{N}_{2}$, and then $10 \mathrm{~mL}$ trimethylchlorosilane (TMCS) was added dropwise under stirring. The mixture was filtered with toluene and ethanol after stirring continuously at $353 \mathrm{~K}$ for 8 hours. After that, the surfactant template was removed by calcination in air at $823 \mathrm{~K}$ for 6 hours. Thus, SBA-15 with the external surface capped with $-\mathrm{Si}\left(\mathrm{CH}_{3}\right)_{3}$ (named cal-TMCS-SBA-15) was collected.

After having been outgassed at $353 \mathrm{~K}$ for 12 hours. $2.0 \mathrm{~g}$ cal-TMCS-SBA-15 was suspended in $150 \mathrm{~mL}$ dry toluene, and then $6.0 \mathrm{~mL} \mathrm{3-aminopropyltrimethoxysilane} \mathrm{(APTMS)}$ was added under stirring. The mixture obtained was stirred for another 12 hours at room temperature and refluxed at $353 \mathrm{~K}$ for 8 hours. The solid was obtained after washing with toluene and then with ethanol intensively to eliminate the physically adsorbed APTMS and toluene. The selectively modified sample after being vacuum-dried at $353 \mathrm{~K}$ for 6 hours was labeled APTMS-TMCS-SBA- 15.

To introduce reducer of formaldehyde into the channels, $1.0 \mathrm{~g}$ APTMS-TMCS-SBA-15 was soaked in a $105 \mathrm{~mL}$ mixture of formaldehyde, ethanol and water (formaldehyde/ethanol/water, $5: 20: 80, \mathrm{v} / \mathrm{v} / \mathrm{v}$ ), and the suspension was stirred at $313 \mathrm{~K}$ for 30 minutes. The product was filtered, rinsed with deionized water and dried at $323 \mathrm{~K}$ for 12 hours and denoted as HCHO-APTMS-TMCS-SBA- 15 .

For $\mathrm{Ag}$ incorporation, $1.0 \mathrm{~g}$ HCHO-APTMS-TMCSSBA-15 was added into a mixture of ethanol and $0.01 \mathrm{M}$ $\mathrm{Ag}\left(\mathrm{NH}_{3}\right)_{2} \mathrm{NO}_{3}$ (aq) $(1: 4, \mathrm{v} / \mathrm{v})$, and then the mixture was stirred at $313 \mathrm{~K}$ for 30 minutes. The product was filtered and rinsed thoroughly with deionized water and dried under vacuum at $323 \mathrm{~K}$ overnight, and thus formed confined silver nanoparticles were noted as Ag- ${ }^{\mathrm{m}} \mathrm{SBA}-15$. 

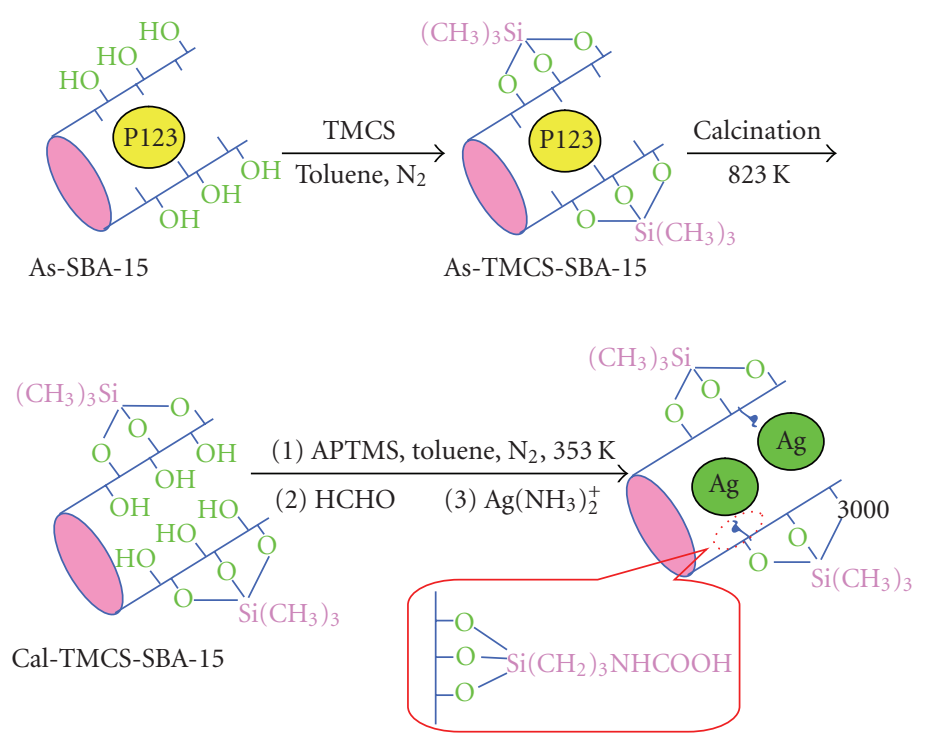

TMCS: $\mathrm{Si}\left(\mathrm{CH}_{3}\right)_{3} \mathrm{Cl}, \mathrm{P} 123: \mathrm{EO}_{20}-\mathrm{PO}_{70}-\mathrm{EO}_{20}$, APTMS: $\mathrm{H}_{2} \mathrm{NCH}_{2} \mathrm{CH}_{2} \mathrm{CH}_{2} \mathrm{Si}\left(\mathrm{OCH}_{3}\right)_{3}$

Scheme 1: Schematic representation of synthesis of Ag-m ${ }^{\mathrm{m} B A-15 .}$

In the control experiment, an aqueous solution of $1 \mathrm{mM}$ $\mathrm{NaBH}_{4}(70 \mathrm{~mL})$ was cooled with ice and then $1 \mathrm{mM} \mathrm{AgNO}$ aqueous solution $(100 \mathrm{~mL})$ was added to it under vigorous stirring, resulting in the light-brown Ag colloidal solution [31]. The product was filtered, rinsed with deionized water, dried and denoted as nm-Ag.

\subsection{Characterization methods}

High-resolution transmission electron microscopy (HRTEM) images were obtained on instruments of FEI TecnaiF30 electron microscopy operating at $300 \mathrm{KV}$. The powder samples were characterized by powder X-ray diffraction (XRD) using a Panalytical X'pert PRO diffractormeter (Tokyo, Japan) equipped with graphite monochromatized $\mathrm{Cu}$ Kalpha radiation. Surface functionalization was monitored by Fourier transformation infrared spectroscopy (FTIR) using a Nicolet FTIR 340 spectrometer. The pore diameter, pore volume, and surface area of the samples were derived from the nitrogen sorption isotherm at $77 \mathrm{~K}$ using a Micromeritics TriStar 3000 system. Prior to measurements, the sample was evacuated at $393 \mathrm{~K}$ for 5 hours. The UVvis absorption was recorded on a Shimadzu UV-2100 spectrometer.

The material Ag- ${ }^{\mathrm{m}}$ SBA-15 was dispersed through ultrasonic vibration in a solution of dichlorethane containing polyvinyl chloride (PVC) to form a suspension. A defined quantity of the suspension was applied to a clean surface of glassy carbon (GC) substrate to form a thin film electrode, noted as Ag- ${ }^{\mathrm{m}} \mathrm{SBA}-15 / \mathrm{GC}$, then dried in the air for about 30 minutes. The solutions were prepared with Millipore water and chemicals of analytical grade. A saturated calomel electrode was used as reference electrode, and all electrochemical experiments were carried out at room temper- ature around $293 \mathrm{~K}$. A CHI-660C potentiostat/galvanostat (Chenhua Instruments, Inc., Shanghai, China) was used in electrochemical studies.

\section{RESULTS AND DISCUSSION}

\subsection{Characterization}

\subsubsection{HRTEM studies}

In our synthesis procedures: (1) before removing the template, the external surface of the SBA-15 was firstly capped by trimethylchlorosilane (TMCS); (2) after removing the template, 3-aminopropyltrimethoxysilane (APTMS) molecules were introduced into the channels of SBA-15, which leads to that the amino functional groups were grafted to the internal walls of SBA-15 channels; (3) the reducers of formaldehyde were then introduced into the channels of SBA-15 and grafted on the amino groups inside the channel; (4) the metal precursors of $\mathrm{Ag}\left(\mathrm{NH}_{3}\right)_{2} \mathrm{NO}_{3}$ were finally introduced into the channels of SBA-15 by diffusion when the modified SBA-15 is put in a solution containing $\mathrm{Ag}\left(\mathrm{NH}_{3}\right)_{2} \mathrm{NO}_{3}$. The silver (0) nanoparticles were, therefore, formed through the reduction of $\mathrm{Ag}$ (I) ions by reducers previously fixed on the internal walls of the SBA-15 channels. Theoretically, Ag nanoparticles prepared by this method were located inside the channel between the walls in the method. The silver nanoparticles assembled inside the channels of SBA-15 can be further confirmed by HRTEM (Figure 1). Figure 1(a) shows the HRTEM of calcinated SBA-15 (cal-SBA-15), in which wellordered channels are illustrated and are characteristic of mesoporous materials. Figure 1(b) depicts the HRTEM of Ag- ${ }^{\mathrm{m}} \mathrm{SBA}-15$, where the highly ordered pore structure of SBA-15 is still preserved. We can observe clearly that silver nanoparticles appear as dark spherical objects between the 


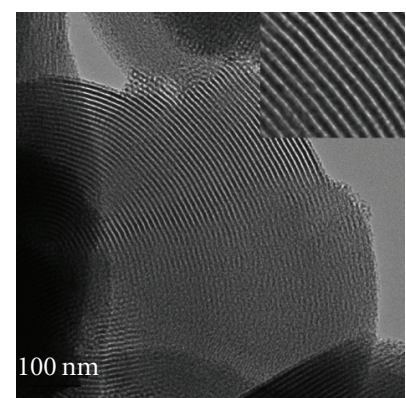

(a)

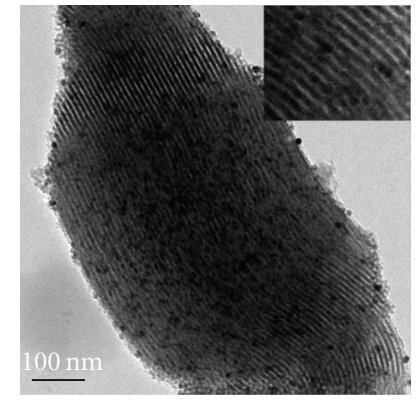

(b)
Figure 1: HRTEM images of (a) cal-SBA-15, (b) Ag- ${ }^{\mathrm{m}}$ SBA-15.

walls of SBA-15 and are homogeneously distributed inside the channels of SBA-15. It can be also seen that the size of $\mathrm{Ag}$ is slightly larger than the channel, which leads to the distortion of the channels.

\subsubsection{XRD studies}

Figure 2(a) gives a small-angle XRD pattern of calcinated SBA-15(cal-SBA-15), three diffraction peaks appear in the spectrum, which are attributed to the characteristic diffraction peaks of (100), (110), and (200) for SBA-15, respectively, due to typical hexangular phase [2, 24]. After reaction with APTMS, the small-angle XRD pattern of APTMSTMCS-SBA-15 (Figure 2(b)) still shows the characteristic diffraction peaks, which exhibits that the grafting of amino groups inside the channels did not affect the long-range ordering of the mesostructures. Compared with cal-SBA15, the peaks shift to lower angles, and such shift may imply the enlargement of the frameworks [32]. The little negative shifting may be aroused by the covalent linkage between APTMS and hydroxy in the channels. We know from BET data in Table 1 the $\mathrm{D}_{\mathrm{BJH}}$ value is almost constant during the covalent linkage, but $\mathrm{D}_{\mathrm{BJH}}$ value has an obviously decrease after Ag nanoparticles were assembled. In addition, after the loading of Ag into APTMS-TMCS-SBA15 (assigned as Ag- ${ }^{\mathrm{m}} \mathrm{SBA}-15$ ), the peaks (Figure 2(c)) have shifted positively comparing with that of APTMS-TMCSSBA-15, the intensity of the peaks has decreased to a certain extent, while the full width at half-maximum (FWHM) of the peaks that is normalized by height has increased. These three features are attributed to contraction of framework during the support treatment, implying that Ag nanoparticles have been introduced into the channel of SBA-15 successfully as discussed elsewhere $[24,33]$. The inset of Figure 2 is wide-angle XRD of Ag- ${ }^{\mathrm{m}} \mathrm{SBA}-15$. The broadening of the Ag diffraction peaks suggests that the size of Ag nanoparticles is in the nanometer range [8]. The average Ag particle size was estimated to be $8.0 \mathrm{~nm}$, from the peak width of Ag (220) reflection by using Scherrer's equation for approximation [34].

\subsubsection{FTIR studies}

FTIR spectroscopy can provide surface information of materials for identification of chemical groups. Figure 3(a)

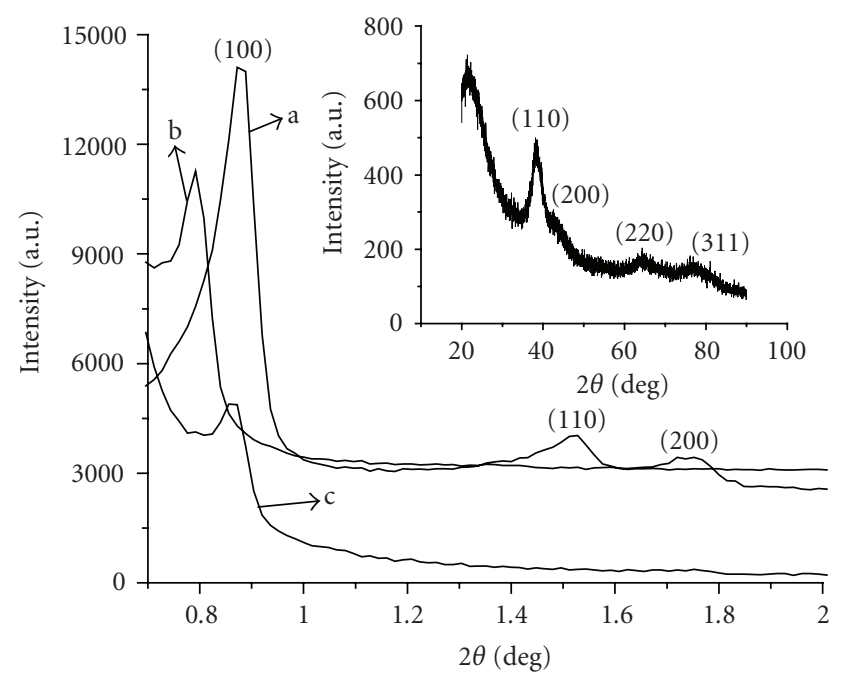

FIGURE 2: Small-angle XRD patterns of (a) cal-SBA-15, (b) APTMSTMCS-SBA-15, and (c) Ag- ${ }^{\mathrm{m}}$ SBA-15. Inset is the wide-angle XRD pattern of Ag- ${ }^{\mathrm{m}} \mathrm{SBA}-15$.

presents the transmission FTIR spectrum of as-SBA-15, in which the bands in $2900-3000 \mathrm{~cm}^{-1}$ were attributed to template P123. After calcination in air at $823 \mathrm{~K}$ for 6 hours (cal-SBA-15), the bands in $2900-3000 \mathrm{~cm}^{-1}$ were disappeared (Figure $3(\mathrm{~b})$ ). This indicates that the template P123 was completely removed. After modification of the outer surface of as-SBA-15 with trimethylchlorosilane (TMCS), the sample was named as-TMCS-SBA-15. Figure 3(c) shows the FTIR spectrum of as-TMCS-SBA-15, in which the bands in $2900-3000 \mathrm{~cm}^{-1}$ attributed to template P123 and TMCS can be seen clearly. However, when the temple of the asTMCS-SBA-15 has been removed by calcination in air at $823 \mathrm{~K}$ for 6 hours as it was done in Figure 2(b), we can still observe the bands in $2900-3000 \mathrm{~cm}^{-1}$ from Figure $3(\mathrm{~d})$, which can be attributed to the $\mathrm{C}-\mathrm{H}$ stretching modes of $\mathrm{CH}_{3}$ in cal-TMCS-SBA-15 [6]. This result confirmed that the methyl groups are still present on the material calTMCS-SBA-15 when template P123 was completely removed at $823 \mathrm{~K}$. Such stability comes from the covalent linkage between $-\mathrm{CH}_{3}$ groups and the hydroxy in the outer surface of silica framework.

The modification process of external surface of as-SBA15 does not affect the internal surface of the channel because the template molecules occupy these channels during the external surface modification. The incorporation of APTMS inside the channels of the SBA-15 has been confirmed by transmission FTIR spectra as shown in Figure 4. The curve $\mathrm{c}$ is the spectrum of APTMS, and we can see the bands in the range $2900-3000 \mathrm{~cm}^{-1}$, which are attributed to the $\mathrm{C}-\mathrm{H}$ stretching modes of $-\mathrm{CH}_{2}$ in APTMS. The curve a is the spectrum of cal-TMCS-SBA-15, in which we can observe the characteristic absorption of Si-O-Si at 1082, $797,465 \mathrm{~cm}^{-1}$ assigned to asymmetric stretching, symmetric stretching, and bend stretching [35]. In addition, the wellknown IR adsorption bands which due to the stretching vibrational mode of surface silanol groups and water in the 
TABLE 1: Physicochemical properties of the samples. $\mathrm{S}_{\mathrm{BET}}$, BET specific surface area; $V_{t}$, total pore volume; $\mathrm{D}_{\mathrm{BJH}}$, pore diameter calculated using BJH method; $\mathrm{d}_{100}$, periodicity of host SBA-15 derived from XRD. The wall thicknesses, $t$, was calculated as $\mathrm{A}_{0}-$ pore size $\left(\mathrm{A}_{0}=\right.$ $2 \mathrm{~d}(100) / \sqrt{3})$.

\begin{tabular}{|c|c|c|c|c|c|c|}
\hline Sample & $\mathrm{S}_{\mathrm{BET}} / \mathrm{m}^{2} \mathrm{~g}^{-1}$ & $V_{t} / \mathrm{cm}^{3} \mathrm{~g}^{-1}$ & $\mathrm{D}_{\mathrm{BJH}} / \mathrm{nm}$ & $\mathrm{d}_{100} / \mathrm{nm}$ & $\mathrm{A}_{0} / \mathrm{nm}$ & $t / \mathrm{nm}$ \\
\hline as-SBA-15 & 262 & 0.41 & 6.00 & 10.92 & 12.61 & 6.61 \\
\hline cal-SBA-15 & 703 & 1.02 & 6.54 & 10.10 & 11.69 & 5.15 \\
\hline cal-TMCS-SBA-15 & 705 & 1.04 & 6.57 & 10.13 & 11.70 & 5.13 \\
\hline APTMS-TMCS-SBA-15 & 419 & 0.68 & 6.49 & 10.15 & 11.72 & 5.34 \\
\hline HCHO-APTMS-TMCS-SBA-15 & 335 & 0.48 & 5.86 & 9.79 & 11.30 & 5.44 \\
\hline Ag-m ${ }^{\mathrm{m}}$ SBA-15 & 232 & 0.30 & 5.05 & 10.11 & 11.67 & 6.62 \\
\hline
\end{tabular}

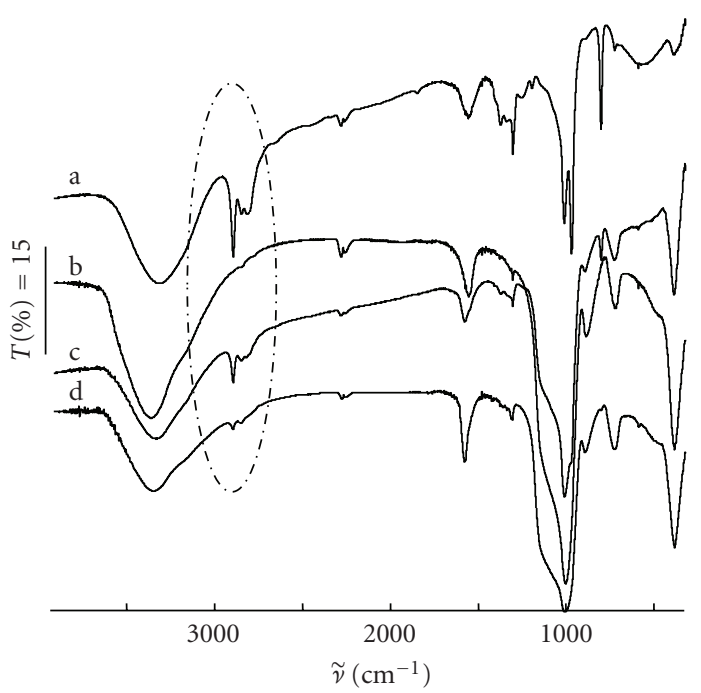

Figure 3: FTIR spectra of (a) cal-SBA-15, (b) cal-TMCS-SBA-15.

range $3500-3740 \mathrm{~cm}^{-1}[36,37]$, and the $\mathrm{C}-\mathrm{H}$ stretching modes of $-\mathrm{CH}_{3}$ in the range $2900-3000 \mathrm{~cm}^{-1}$ [6] were also seen. The curve $b$ showed the spectrum that APTMS was introduced into the channel of cal-TMCS-SBA-15, in which the intensity of IR absorption decrease for silanol group at 3500-3740 $\mathrm{cm}^{-1}$, and the intensity of IR absorption increase for the C-H group at $2900-3000 \mathrm{~cm}^{-1}$. The ratio of integrated intensity of the $\mathrm{Si}-\mathrm{OH}$ band $\left(\mathrm{I}_{\mathrm{Si}-\mathrm{OH}}\right)$ to integrated intensity of the $\mathrm{C}-\mathrm{H}$ band $\left(\mathrm{I}_{\mathrm{C}-\mathrm{H}}\right)$, that is, $\mathrm{I}_{\mathrm{Si}-\mathrm{OH}} / \mathrm{I}_{\mathrm{C}-\mathrm{H}}$, can be used to evaluate the increase of $-\mathrm{CH}_{2}$ and $-\mathrm{CH}_{3}$ and decrease of silanol due to the introduction of APTMS inside the channel of SBA-15. And the change of $\mathrm{I}_{\mathrm{Si}-\mathrm{OH}} / \mathrm{I}_{\mathrm{C}-\mathrm{H}}$ can be used to monitor the reaction process between $\mathrm{Si}-$ $\mathrm{OH}$ and APTMS, since the intensity of the $\mathrm{Si}-\mathrm{OH}$ band decreases and the intensity of the $\mathrm{C}-\mathrm{H}$ band increases with the reaction progressing. Here, $\mathrm{I}_{\mathrm{Si}-\mathrm{OH}} / \mathrm{I}_{\mathrm{C}-\mathrm{H}}$ is reduced from 38.1 at cal-TMCS-SBA-15 to 16.0 at APTMS-TMCS-SBA15. The decrease of integrated intensity of silanol groups demonstrates an anchoring mechanism (see Scheme 1) involving reaction between $\mathrm{Si}-\mathrm{OH}$ and APTMS [38].

\subsubsection{Nitrogen adsorption/desorption isotherms}

Nitrogen adsorption/desorption isotherms for as-SBA15, cal-SBA-15, cal-TMCS-SBA-15, APTMS-TMCS-SBA-15,

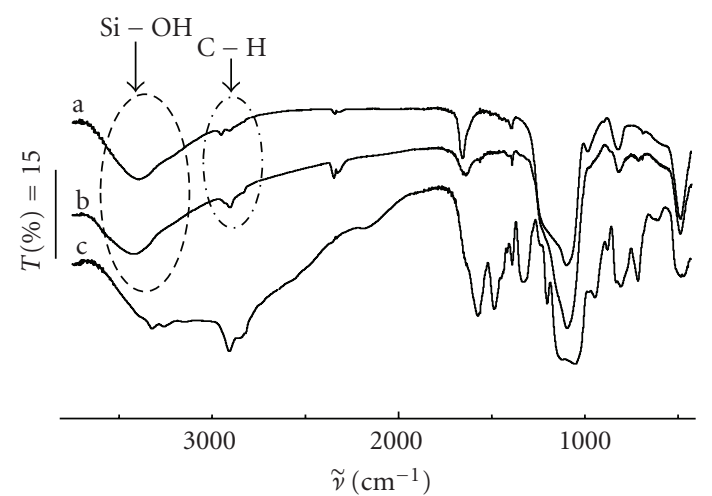

FIGURE 4: FTIR spectra of (a) cal-TMCS-SBA-15, (b) APTMSTMCS-SBA-15, and (c) APTMS.

HCHO-APTMS-TMCS-SBA-15, and Ag- ${ }^{\mathrm{m}}$ SBA-15 are found to be type IV isotherm curves with distinct hysteresis loops and steep adsorption/desorption steps were recorded that indicate a narrow pore size distribution. This suggests that the host silica was still maintained during the modification. Table 1 summarizes the results of $\mathrm{N}_{2}$ desorption analyses. The specific surface area $\left(\mathrm{S}_{\mathrm{BET}}\right.$ ) of as-SBA-15 is $262 \mathrm{~m}^{2} / \mathrm{g}$. After silanols on the external surface of as-SBA-15 were capped by $-\mathrm{Si}\left(\mathrm{CH}_{3}\right)_{3}$ groups, and the template was removed by calcination, $\mathrm{S}_{\mathrm{BET}}$ increases to $705 \mathrm{~m}^{2} / \mathrm{g}$. The total pore volume $\left(V_{t}\right)$, and the average pore size $\left(\mathrm{D}_{\mathrm{BJH}}\right)$ also show an increased value. After silanols on the internal surface of SBA-15 were grafted by 3-aminopropyltrimethoxysilane (APTMS), $\mathrm{S}_{\mathrm{BET}}$ and $V_{t}$ of APTMS-TMCS-SBA-15 decrease from 705 to $419 \mathrm{~m}^{2} / \mathrm{g}$ and from 1.04 to $0.68 \mathrm{~cm}^{3} / \mathrm{g}$, respectively, with a slight decrease of the $\mathrm{D}_{\mathrm{BJH}}$ from 6.57 to $6.49 \mathrm{~nm}$. A considerable decrease in the $\mathrm{S}_{\mathrm{BET}}, V_{t}$, and $\mathrm{D}_{\mathrm{BJH}}$ was measured in Ag- ${ }^{\mathrm{m} S B A}-15$ due to the incorporation of $\mathrm{Ag}$ nanoparticles. The values of $\mathrm{S}_{\mathrm{BET}}, V_{t}$, and $\mathrm{D}_{\mathrm{BJH}}$ for HCHO-APTMS-TMCS-SBA-15 are $335 \mathrm{~m}^{2} / \mathrm{g}, 0.48 \mathrm{~cm}^{3} / \mathrm{g}$, and $5.86 \mathrm{~nm}$, whereas they are $232 \mathrm{~m}^{2} / \mathrm{g}, 0.30 \mathrm{~cm}^{3} / \mathrm{g}$, and $5.05 \mathrm{~nm}$ for $\mathrm{Ag}_{-}{ }^{\mathrm{m}} \mathrm{SBA}-15$. All these, together with the increased thickness of pore walls $(t)$, can be attributed to the pore-filling effect $[14,39]$ and the fact demonstrated that the Ag nanoparticles have been confined inside the channel of SBA-15 [4].

The silver nanoparticles were synthesized in the inner surface of silica framework by the "ship-in-a-bottle" 


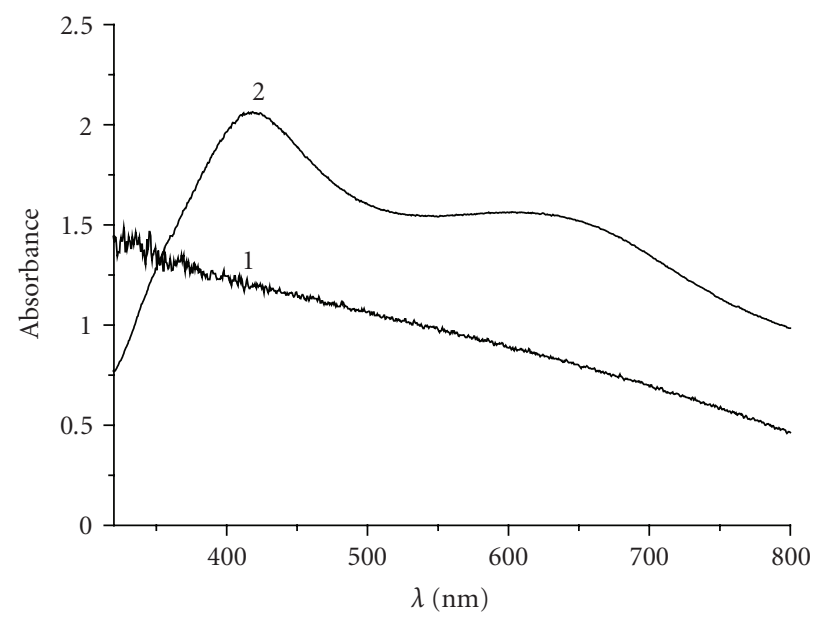

(a)

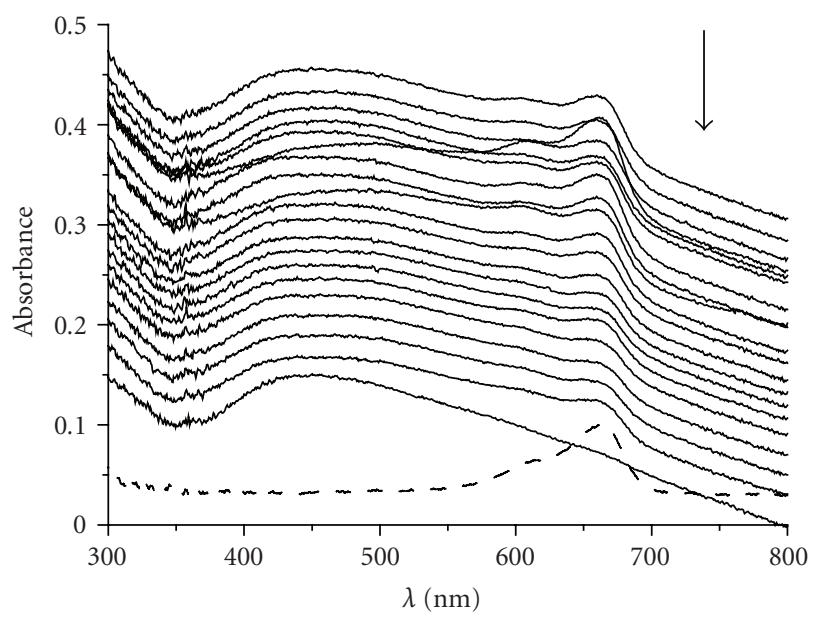

(b)

FIgure 5: (a) UV-vis spectra of (line 1) APTMS-TMCS-SBA-15 and (line 2) Ag- ${ }^{\mathrm{m}}$ SBA-15 immerged in $1 \mathrm{M}$ NaOH solution, (b) Successive UV-vis spectra (taken every 1 minute) of methylene blue (MB) dye reduction, using silica SBA-15 containing silver nanoparticles (Ag- ${ }^{\mathrm{m}}$ SBA15) as the catalyst and $\mathrm{NaBH}_{4}$ as the reducing agent. UV-vis spectrum of $\mathrm{MB}$ dye with pure silica SBA-15, using $\mathrm{NaBH}_{4}$ as the reducing agent (dash line).

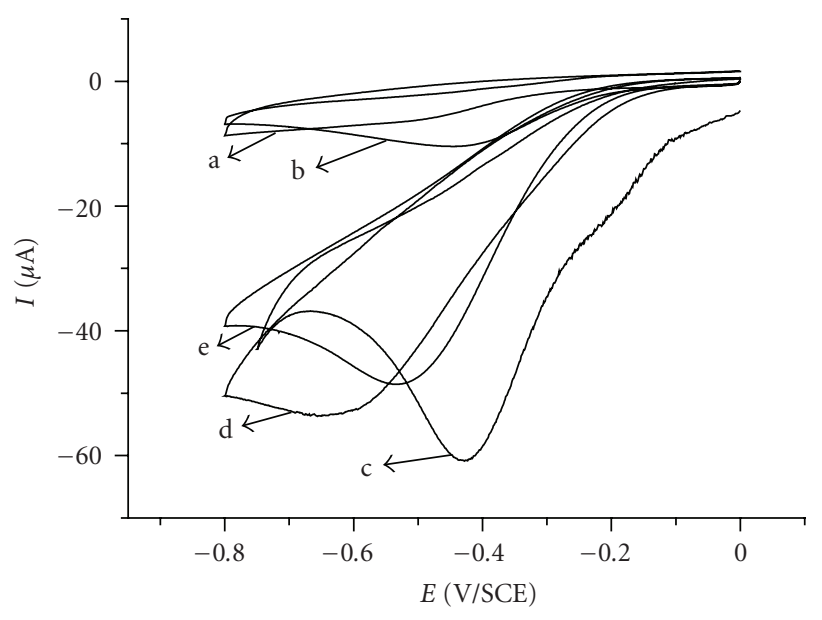

FIgUre 6: The voltammetric response of (a) $\mathrm{GC}$ to $3 \mathrm{mM} \mathrm{H}_{2} \mathrm{O}_{2}$, (b) Ag- ${ }^{\mathrm{m}} \mathrm{SBA}-15 / \mathrm{GC}$ to $0 \mathrm{mM} \mathrm{H}_{2} \mathrm{O}_{2}$, (c) Ag- ${ }^{\mathrm{m}} \mathrm{SBA}-15 / \mathrm{GC}$ to $3 \mathrm{mM}$ $\mathrm{H}_{2} \mathrm{O}_{2}$, (d) nm-Ag/GC to $3 \mathrm{mM} \mathrm{H}_{2} \mathrm{O}_{2}$, and (e) bulk Ag to $3 \mathrm{mM}$ $\mathrm{H}_{2} \mathrm{O}_{2}$. All experiments were carried out in $0.2 \mathrm{M} \mathrm{HAc-NaAc}$ buffer $(\mathrm{pH}=5)$ electrolyte, scan rate: $50 \mathrm{mV} \cdot \mathrm{s}^{-1}$.

approach, in which the channel of SBA-15 is used as a microreactor to prepare the nanoparticles. Precursors were introduced into the channels one by one, and were assembled into Ag nanoparticles in the microreactor. This resulted in the Ag nanoparticles were confined inside the channel of SBA-15. Silanols on the external surface of as-SBA15 were first capped by $-\mathrm{Si}\left(\mathrm{CH}_{3}\right)_{3}$ groups. After removal of the template of capped SBA-15 by calcination, silanols on the internal surface of SBA-15 were modified by 3aminopropyltrimethoxysilane (APTMS), and then formaldehyde was grafted by amino groups of APTMS to form $\mathrm{NHCH}_{2} \mathrm{OH}$ species, on which $\mathrm{Ag}\left(\mathrm{NH}_{3}\right)_{2} \mathrm{NO}_{3}$ could be in situ reduced into $\mathrm{Ag}$ nanoparticles. Without silanols on the surface of SBA-15, there will be impossible to form $\mathrm{NHCH}_{2} \mathrm{OH}$ species, and further to produce Ag nanoparticles. So there will be no Ag nanoparticles on the external surface of SBA-15 thanks to silanols on the external surface first capped by $-\mathrm{Si}\left(\mathrm{CH}_{3}\right)_{3}$ groups to decrease its activity. $\mathrm{D}_{\mathrm{BJH}}$ of APTMS-TMCS-SBA-15 is $6.49 \mathrm{~nm}$ from BET data, and the average Ag nanoparticle size was estimated to be $8.0 \mathrm{~nm}$ from XRD analysis. HRTEM image has also demonstrated that the size of Ag is slightly larger than the channel, which leads to the distortion of the channels. Therefore, we infer that the channels are slightly distorted during the nanoparticles synthesized in the microreactor, which makes the size of nanoparticles prepared inside the channel of SBA-15 larger than the size of the channel diameter. As a result, the problem of catalyst leaking is much lessened or eliminated. Similar results have been also reported in literature [40].

\subsubsection{UV-vis absorption spectroscopic studies}

UV-vis absorption spectra of the Ag- ${ }^{\mathrm{m}} \mathrm{SBA}-15$ samples may be used to provide additional evidence of the formation of $\mathrm{Ag}$ nanostructures inside the channels of SBA-15 powder and reveal unique optical properties. Figure 5(a) (line 1) shows the UV-vis absorption spectrum of HCHO-APTMSTMCS-SBA-15, in which a spectrum with a nearly linear was recorded. Figure 5(a) (line 2) shows the absorption spectrum of Ag- ${ }^{\mathrm{m}} \mathrm{SBA}-15$, in which only the peak of $420 \mathrm{~nm}$ which assigned to the surface plasmon resonance (SPR) of Ag nanoparticles [16] is observed and the peak of $345 \mathrm{~nm}$ assigned to small silver clusters from 2 to 8 atoms formed in micropores of silica walls [41] is absent. SPR is a characteristic feature of metal nanoparticles between the sizes of 2 and $50 \mathrm{~nm}$ [42]. This result indicates that the reduction of silver (I) ions in the micropores of the SBA-15 


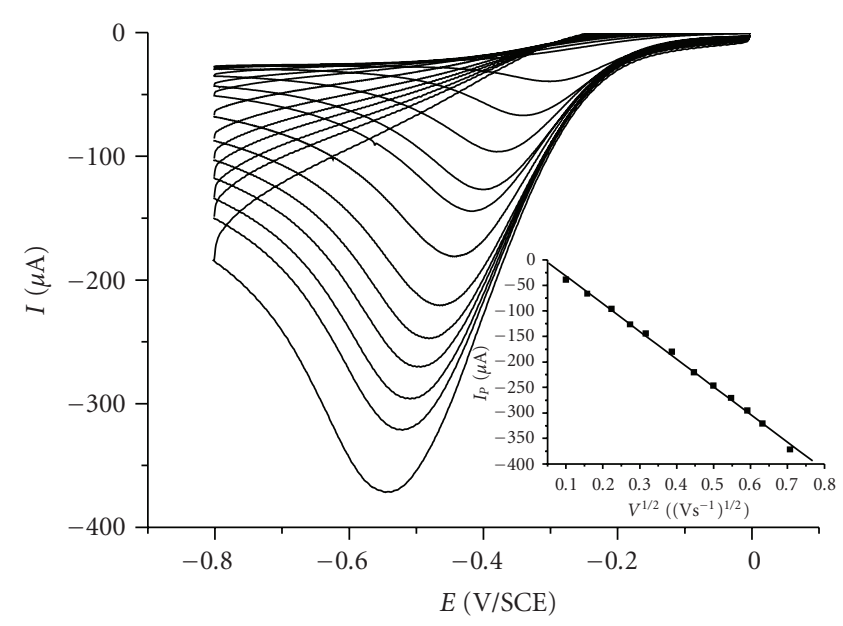

FIgURE 7: The cyclic voltammograms of $\mathrm{Ag}^{-}{ }^{\mathrm{m}} \mathrm{SBA}-15 / \mathrm{GC}$ in $0.2 \mathrm{M}$ HAc-NaAc buffer $(\mathrm{pH}=5)+3 \mathrm{mM} \mathrm{H}_{2} \mathrm{O}_{2}$, at different scan rates (from upper to lower): 10, 25, 50, 75, 100, 150, 200, 250, 300, 350, $400,500 \mathrm{mV} \cdot \mathrm{s}^{-1}$, respectively. Inset is plot of peak current versus $\mathrm{v}^{1 / 2}$.

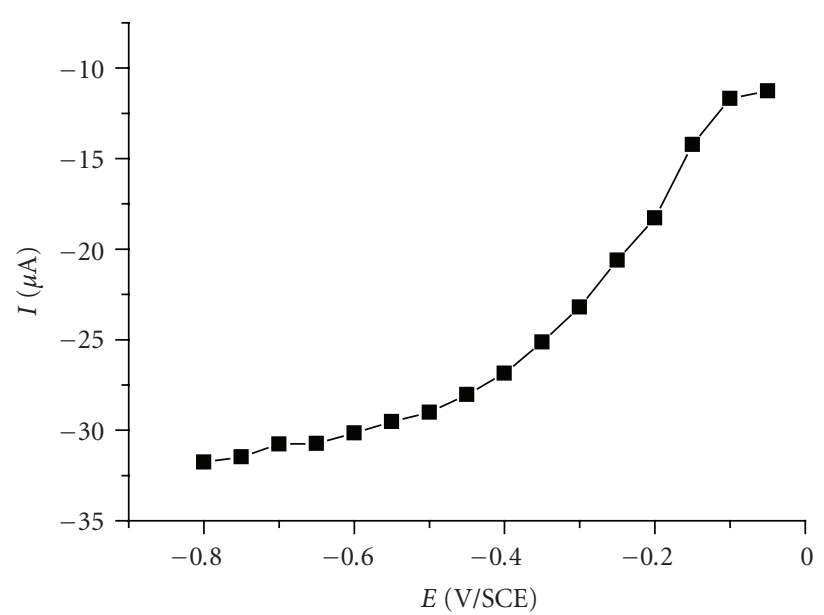

FIGURE 8: Influence of applied potential on amperometric response of Ag- ${ }^{\mathrm{m}} \mathrm{SBA}-15 / \mathrm{GC}$ in $0.2 \mathrm{M} \mathrm{HAc-NaAc}$ buffer $(\mathrm{pH}=5)+3 \mathrm{mM}$ $\mathrm{H}_{2} \mathrm{O}_{2}$.

does not exist, since all the reducers were introduced into the mesopores of the SBA-15 in our experiment.

Moreover, silver nanoparticles have been studied as a catalyst in reduction reactions of dyes like methylene blue (MB) [43]. Here, reduction of $\mathrm{MB}$ by $\mathrm{NaBH}_{4}$ is used as a standard for determining the catalytic activity of Ag- ${ }^{\mathrm{m}} \mathrm{SBA}-$ 15. The preliminary catalytic testing for Ag- ${ }^{\mathrm{m}} \mathrm{SBA}-15$ was carried out by reduction of $\mathrm{MB}\left(2 \mathrm{~mL} 10^{-5} \mathrm{M}\right)$ in water using Ag- ${ }^{\mathrm{m}} \mathrm{SBA}-15(1 \mathrm{mg})$ as catalyst and $\mathrm{NaBH}_{4}\left(1 \mathrm{~mL} 10^{-4} \mathrm{M}\right)$ as the reducing agent. The progression of the catalytic reduction of $\mathrm{MB}$ can be easily followed by the change of absorbance intensity at $665 \mathrm{~nm}$ that is absorbance maximum $\left(\lambda_{\max }\right)$ of MB. The dot line in Figure $4(\mathrm{~b})$ is the UV-vis spectrum of the mixture containing a mixture of $\mathrm{MB}$ dye plus $\mathrm{NaBH}_{4}$ reducing agent, with pure silica SBA-15, which gives a strong peak at $665 \mathrm{~nm}$ attributing to $\lambda_{\max }$ of $\mathrm{MB}$, illustrating that $\mathrm{MB}$ have not been reduced. When $1 \mathrm{mg}$ Ag- ${ }^{\mathrm{m}} \mathrm{SBA}-15$ was added into above solution, it can be seen the band at $420 \mathrm{~nm}$ attributing to the SPR of Ag nanoparticles Figure 5(b) (solid line). The absorbance at $\lambda_{\max }$ of MB gradually decreases with the reaction time, which suggests $\mathrm{MB}$ begin to reduce, and meanwhile we can observe the color of solution changes from blue to colorless. Above investigations have illustrated that silver nanoparticles exhibit a high catalytic activity to the reduction of $\mathrm{MB}$.

\subsection{Application of $\mathrm{Ag}^{-\mathrm{m}} \mathrm{SBA}-15$ as a sensor for detecting hydrogen peroxide}

\subsubsection{Electrochemical response of $\mathrm{Ag}-{ }^{\mathrm{m}} \mathrm{SBA}-15 / \mathrm{GC}$ electrode to reduction of $\mathrm{H}_{2} \mathrm{O}_{2}$}

Figure 6(a) displayed the cyclic voltammetry (CV) of glassy carbon (GC) in $0.2 \mathrm{M} ;$ ? bmbox? ¿HAc-NaAci?mbox?; buffer solution ( $\mathrm{pH}$ ) containing $3 \mathrm{mM} \mathrm{H}_{2} \mathrm{O}_{2}$, in which a featureless CV was observed, and the current may be mainly ascribed to the double-layer charging of the electrode. Figure 6(b) is CV of Ag- ${ }^{\mathrm{m}} \mathrm{SBA}-15 / \mathrm{GC}$ in $0.2 \mathrm{M} \mathrm{HAc-NaAc}$ buffer solution ( $\mathrm{pH} 5)$, in which a small reduction current appears that may be attributing to reduction of support electrolyte. Figures 6(c), 6(d), and 6(e) show the CVs of Ag${ }_{\mathrm{m}} \mathrm{SBA}-15 / \mathrm{GC}, \mathrm{nm}-\mathrm{Ag} / \mathrm{GC}$, and bulk Ag, respectively, in $0.2 \mathrm{M}$ $\mathrm{HAc}-\mathrm{NaAc}+3 \mathrm{mM} \mathrm{H}_{2} \mathrm{O}_{2}$. It can be seen a wave at $-0.42 \mathrm{~V}$ for Ag- ${ }^{\mathrm{m}} \mathrm{SBA}-15 / \mathrm{GC},-0.65 \mathrm{~V}$ for $\mathrm{nm}-\mathrm{Ag} / \mathrm{GC}$, and $-0.53 \mathrm{~V}$ for bulk Ag appear. Ag- ${ }^{\mathrm{m}} \mathrm{SBA}-15 / \mathrm{GC}, \mathrm{nm}-\mathrm{Ag} / \mathrm{GC}$, and bulk $\mathrm{Ag}$ electrode on the initial reduction potential of $\mathrm{H}_{2} \mathrm{O}_{2}$ is $-0.12 \mathrm{~V},-0.15 \mathrm{~V}$, and $-0.17 \mathrm{~V}$, respectively. The reduction potential of $\mathrm{H}_{2} \mathrm{O}_{2}$ on $\mathrm{Ag}-{ }^{\mathrm{m}} \mathrm{SBA}-15 / \mathrm{GC}$ was $140 \mathrm{mV}, 230 \mathrm{mV}$, and $110 \mathrm{mV}$ more negative than that on silver nanoparticles assembles supported on GC [44], nm-Ag/GC, and bulk $\mathrm{Ag}$, indicating a lower overpotential for $\mathrm{H}_{2} \mathrm{O}_{2}$ reduction at the Ag- ${ }^{\mathrm{m}} \mathrm{SBA}-15 / \mathrm{GC}$. Figure 7 depicts the CVs of Ag- ${ }^{\mathrm{m}} \mathrm{SBA}-$ $15 / \mathrm{GC}$ in $0.2 \mathrm{M} \mathrm{HAc}-\mathrm{NaAc}+3 \mathrm{mM} \mathrm{H}_{2} \mathrm{O}_{2}$ with different scan rate. It can be seen that the peak currents of the $\mathrm{H}_{2} \mathrm{O}_{2}$ reduction increase in $\mathrm{Ag}_{-}{ }^{\mathrm{m}} \mathrm{SBA}-15 / \mathrm{GC}$ in $0.2 \mathrm{M} \mathrm{HAc-NaAc}$ $+3 \mathrm{mM} \mathrm{H}_{2} \mathrm{O}_{2}$ with an increasing scan rate. In the scan rate range from $10 \mathrm{mV} \cdot \mathrm{s}^{-1}$ to $500 \mathrm{mV} \cdot \mathrm{s}^{-1}$, the reduction current of $\mathrm{H}_{2} \mathrm{O}_{2}$ is proportional to the square root of scan rate (inset of Figure 7), which suggests that the rate of electrochemical reaction is rather fast and the electrode process is controlled by the diffusion of $\mathrm{H}_{2} \mathrm{O}_{2}$ from solution to electrode surface. In order to determine the optimal working potential for the $\mathrm{H}_{2} \mathrm{O}_{2}$ sensing, the electrochemical response of the $\mathrm{H}_{2} \mathrm{O}_{2}$ was researched in different potentials. The relationship between the steady-state current and the operating potential in $0.2 \mathrm{M} \mathrm{HAc}-\mathrm{NaAc}+3 \mathrm{mM} \mathrm{H}_{2} \mathrm{O}_{2}$ at Ag- ${ }^{\mathrm{m}} \mathrm{SBA}-15 / \mathrm{GC}$ is showed in Figure 8. Considering the economy of energy, the sensitivity and the steadiness of Ag- ${ }^{\mathrm{m} S B A}-15 / \mathrm{GC},-0.45 \mathrm{~V}$ were chosen as optimal working potential for $\mathrm{H}_{2} \mathrm{O}_{2}$ sensing with amperometry of constant potential.

\subsubsection{Detection of $\mathrm{H}_{2} \mathrm{O}_{2}$}

Figure 9 (a) shows the dynamic response of the Ag- ${ }^{m}$ SBA$15 /$ GC modified electrode at a working potential of $-0.45 \mathrm{~V}$ 


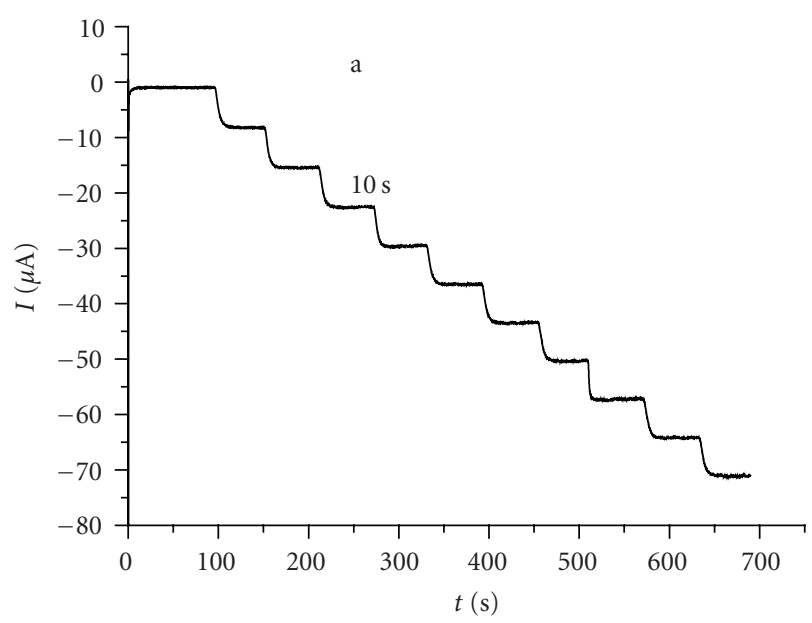

(a)

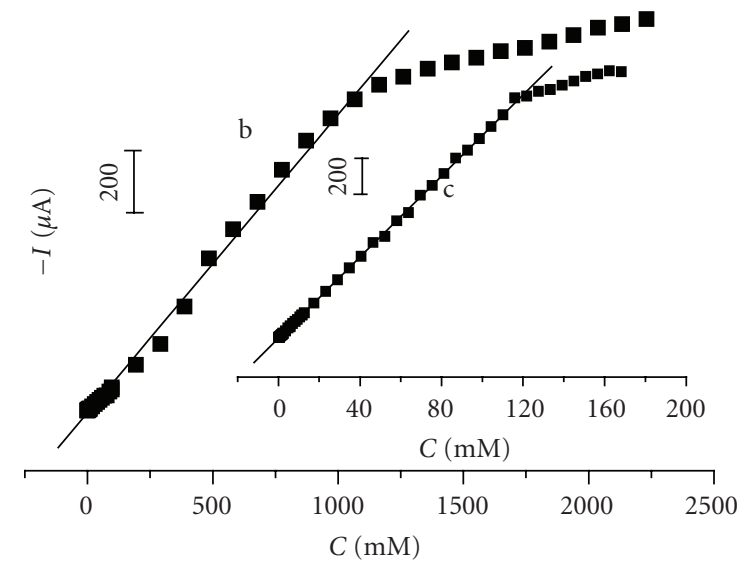

(b)

Figure 9: (a) Typical amperometric response of sensor at $-0.45 \mathrm{~V}$ to successive addition of $3 \mathrm{mM} \mathrm{H}_{2} \mathrm{O}_{2}$ to $0.2 \mathrm{M} \mathrm{HAc-NaAc} \mathrm{buffer}$ ( $\mathrm{pH}=5$ ), (b) calibration plot between the steady-state current and $\mathrm{H}_{2} \mathrm{O}_{2}$ concentration. Inset is Eadie-Hofstee plot between the steady-state current and $\mathrm{H}_{2} \mathrm{O}_{2}$ concentration obtained from the upper limit of the linear range.

with successive injections of $3 \mathrm{mM} \mathrm{H}_{2} \mathrm{O}_{2}$ in $0.2 \mathrm{M} \mathrm{HAc}$ $\mathrm{NaAc}$ buffer solution ( $\mathrm{pH}$ 5). The calibration curve of AgmSBA-15/GC modified electrode under the optimal working potential of $-0.45 \mathrm{~V}$ is showed in Figure $9(\mathrm{~b})$. Under an exactly same condition, the Ag- ${ }^{\mathrm{m}} \mathrm{SBA}-15 / \mathrm{GC}$ modified electrode for $\mathrm{H}_{2} \mathrm{O}_{2}$ determination exhibits a linear range of $4.8 \times 10^{-5}--9.7 \times 10^{-1} \mathrm{M}$ with a detection limit of $1.2 \times 10^{-5} \mathrm{M}(\mathrm{S} / \mathrm{N}=3)$, and analytical time of 10 seconds per sample. The relative standard deviation (RSD) is $2.8 \%$ for ten repetitive measurements of $3 \mathrm{mM} \mathrm{H}_{2} \mathrm{O}_{2}$ solution. While the amperometric response of the bulk Ag electrode to $\mathrm{H}_{2} \mathrm{O}_{2}$ shows a narrower linear relation in the range of $1.2 \times 10^{-4}-$ $-1.1 \times 10^{-1} \mathrm{M}$ with a detection limit of $6.8 \times 10^{-5} \mathrm{M}$, and analytical time of 10 seconds per sample.

The reproducibility and storage stability of the sensor were examined. When Ag- ${ }^{\mathrm{m}} \mathrm{SBA}-15 / \mathrm{GC}$ modified electrode was stored in air and subjected to the day-by-day calibrations at room temperature, the electrode can maintain over $97 \%$ of the initial value in the response to $3.0 \mathrm{mM} \mathrm{H}_{2} \mathrm{O}_{2}$ after 100 days, while the bulk Ag electrode decayed quickly to
92\% after 24 hours. Since the size of silver nanoparticles synthesized inside the channel of SBA-15 is larger than the channel diameter, the problem of catalyst leaking is much lessened or eliminated. In addition, silver nanoparticles were confined inside the channel of SBA-15, which made the catalyst stable and anticontaminated.

As a comparison, we have modified also the synthesis procedures of Ag-mSBA-15 simply skipping the step TMCS treatment. In this case, both inside and outside of the SBA-15 channels were grafted by reducers, and Ag (0) nanoparticles were produced both inside and outside of the SBA-15 channels. We have tested the stability of this sample; and the results demonstrated that its activity for $\mathrm{H}_{2} \mathrm{O}_{2}$ reduction was declined at the first 15 days, then stabilized for long time as the sample of Ag- ${ }^{m}$ SBA-15. The results confirmed that the Ag (0) nanoparticles inside the SBA-15 channels are stable, while those outside the SBA-15 channels are less stable.

In the experimental, it may be always difficult to attain an entire consistent with the theoretical design of preparation of the catalyst. So, a small portion of sites in external 
surface of the SBA-15 may not have been capped by trimethylchlorosilane (TMCS), and lead to form some Ag (0) nanoparticles outside the SBA-15. However, as reported in UV-vis spectra, we have not observed the peak at $345 \mathrm{~nm}$ in UV-vis spectra of samples, which indicated that the quantity of clusters from 2 to 8 atoms could be neglected. In addition, if a small quantity of $\mathrm{Ag}(0)$ nanoparticles were formed outside the SBA- 15 channels, they are not stable. As a consequence, they will not affect the stability of the sensor that uses the $\mathrm{Ag}(0)$ nanoparticles catalysts confined in the SBA-15 channels.

\section{CONCLUSIONS}

The new application of the stabilizer-free silver nanoparticles confined inside the channel of SBA-15 mesoporous silica (Ag- $\left.{ }^{\mathrm{m}} \mathrm{SBA}-15\right)$ is proposed. The uniform mesostructures, high surface areas, and tunable pore sizes of SBA- 15 facilitates its manipulation for sensor preparation and sensing application. The resulting Ag- ${ }^{\mathrm{m}} \mathrm{SBA}-15$ modified electrode shows a very efficient electrocatalytic behavior toward the reduction of $\mathrm{H}_{2} \mathrm{O}_{2}$ at a low overpotential. The sensor for $\mathrm{H}_{2} \mathrm{O}_{2}$ exhibits very good analytical performance with low cost, convenient preparation, and sensitive and rapid detection. Thus, the $\mathrm{Ag}^{-}{ }^{\mathrm{m}} \mathrm{SBA}-15 / \mathrm{GC}$ is an attractive amperometric sensor for $\mathrm{H}_{2} \mathrm{O}_{2}$ and other practical applications.

\section{ACKNOWLEDGMENT}

The study was supported by grants from Natural Science Foundation of China (20433040, 20573085).

\section{REFERENCES}

[1] C. T. Kresge, M. E. Leonowicz, W. J. Roth, J. C. Vartuli, and J. S. Beck, "Ordered mesoporous-sieves synthesized by a liquidcrystal template mechanism,” Nature, vol. 359, pp. 710-712, 1992.

[2] D. Zhao, J. Feng, Q. Huo, et al., "Triblock copolymer syntheses of mesoporous silica with periodic 50 to 300 angstrom pores," Science, vol. 279, no. 5350, pp. 548-552, 1998.

[3] J. Sun, D. Ma, H. Zhang, et al., "Toward monodispersed silver nanoparticles with unusual thermal stability," Journal of the American Chemical Society, vol. 128, no. 49, pp. 15756-15764, 2006.

[4] L.-X. Zhang, J.-L. Shi, J. Yu, Z.-L. Hua, X.-G. Zhao, and M.L. Ruan, "A new in-situ reduction route for the synthesis of Pt nanoclusters in the channels of mesoporous silica SBA-15," Advanced Materials, vol. 14, no. 20, pp. 1510-1513, 2002.

[5] L. Li, J.-L. Shi, L.-X. Zhang, L.-M. Xiong, and J.-N. Yan, "A novel and simple in-situ reduction route for the synthesis of an ultra-thin metal nanocoating in the channels of mesoporous silica materials," Advanced Materials, vol. 16, no. 13, pp. 1079 1082, 2004.

[6] C.-M. Yang, P.-H. Liu, Y.-F. Ho, C.-Y. Chiu, and K.-J. Chao, "Highly dispersed metal nanoparticles in functionalized SBA15," Chemistry of Materials, vol. 15, no. 1, pp. 275-280, 2003.

[7] S.-W. Song, K. Hidajat, and S. Kawi, "Functionalized SBA15 materials as carriers for controlled drug delivery: influence of surface properties on matrix-drug interactions," Langmuir, vol. 21, no. 21, pp. 9568-9575, 2005.
[8] Y. Bai, H. Yang, W. Yang, Y. Li, and C. Sun, "Gold nanoparticles-mesoporous silica composite used as an enzyme immobilization matrix for amperometric glucose biosensor construction," Sensors and Actuators B, vol. 124, no. 1, pp. 179186, 2007.

[9] H. H. P. Yiu, P. A. Wright, and N. P. Botting, "Enzyme immobilisation using SBA-15 mesoporous molecular sieves with functionalised surfaces," Journal of Molecular Catalysis B, vol. 15, no. 1-3, pp. 81-92, 2001.

[10] H. Song, R. M. Rioux, J. D. Hoefelmeyer, et al., "Hydrothermal growth of mesoporous SBA-15 silica in the presence of PVPstabilized Pt nanoparticles: synthesis, characterization, and catalytic properties," Journal of the American Chemical Society, vol. 128, no. 9, pp. 3027-3037, 2006.

[11] P.-H. Liu, Y.-P. Chang, T.-H. Phan, and K.-J. Chao, "The morphology and size of nanostructured $\mathrm{Au}$ in Au/SBA-15 affected by preparation conditions," Materials Science and Engineering C, vol. 26, no. 5-7, pp. 1017-1022, 2006.

[12] C.-W. Chiang, A. Wang, and C.-Y. Mou, "CO oxidation catalyzed by gold nanoparticles confined in mesoporous aluminosilicate Al-SBA-15: pretreatment methods," Catalysis Today, vol. 117, no. 1-3, pp. 220-227, 2006.

[13] C.-W. Chiang, A. Wang, B.-Z. Wan, and C.-Y. Mou, "High catalytic activity for $\mathrm{CO}$ oxidation of gold nanoparticles confined in acidic support Al-SBA-15 at low temperatures," Journal of Physical Chemistry B, vol. 109, no. 38, pp. 1804218047, 2005.

[14] N. Petkov, N. Stock, and T. Bein, "Gold electroless reduction in nanosized channels of thiol-modified SBA-15 material," Journal of Physical Chemistry B, vol. 109, no. 21, pp. 1073710743, 2005.

[15] T. Asefa and R. B. Lennox, "Synthesis of gold nanoparticles via electroless deposition in SBA-15," Chemistry of Materials, vol. 17, no. 10, pp. 2481-2483, 2005.

[16] W. Zhu, Y. Han, and L. An, "Silver nanoparticles synthesized from mesoporous Ag/SBA-15 composites," Microporous and Mesoporous Materials, vol. 80, no. 1-3, pp. 221-226, 2005.

[17] Y.-X. Jiang, N. Ding, and S.-G. Sun, "Enhanced IR absorption of CO adsorbed on Pd nanoparticles embedded in the mesoporous molecular sieve SBA-15," Journal of Electroanalytical Chemistry, vol. 563, no. 1, pp. 15-21, 2004.

[18] Y. Lou, H. Wang, Q. Zhang, and Y. Wang, "SBA-15-supported molybdenum oxides as efficient catalysts for selective oxidation of ethane to formaldehyde and acetaldehyde by oxygen," Journal of Catalysis, vol. 247, no. 2, pp. 245-255, 2007.

[19] R. M. Riouxa, H. Songa, M. Grassa, et al., "Monodisperse platinum nanoparticles of well-defined shape: synthesis, characterization, catalytic properties and future prospects," Topics in Catalysis, vol. 39, no. 3-4, pp. 168-172, 2006.

[20] A. Vinu, K. Z. Hossain, and K. Ariga, "Recent advances in functionalization of mesoporous silica," Journal of Nanoscience and Nanotechnology, vol. 5, no. 3, pp. 347-371, 2005.

[21] A. Walcarius, M. Etienne, and B. Lebeau, "Rate of access to the binding sites in organically modified silicates. 2. Ordered mesoporous silicas grafted with amine or thiol groups," Chemistry of Materials, vol. 15, no. 11, pp. 2161-2173, 2003.

[22] A. Walcarius, M. Etienne, S. Sayen, and B. Lebeau, "Grafted silicas in electroanalysis: amorphous versus ordered mesoporous materials," Electroanalysis, vol. 15, no. 5-6, pp. 414-421, 2003.

[23] Y. Wan, D. Zhang, N. Hao, and D. Zhao, "Organic groups functionalised mesoporous silicates," International Journal of Nanotechnology, vol. 4, no. 1-2, pp. 66-99, 2007. 
[24] Z.-F. Chen, Y.-X. Jiang, Y. Wang, J.-M. Xu, L.-Y. Jin, and S.G. Sun, "Electrocatalytic oxidation of carbon monoxide and methanol at Pt nanoparticles confined in SBA-15: voltammetric and in situ infrared spectroscopic studies," Journal of Solid State Electrochemistry, vol. 9, no. 5, pp. 363-370, 2005.

[25] J. Yuan and A. M. Shiller, "Determination of subnanomolar levels of hydrogen peroxide in seawater by reagent-injection chemiluminescence detection," Analytical Chemistry, vol. 71, no. 10, pp. 1975-1980, 1999.

[26] E. C. Hurdis and H. Romeyn Jr., "Accuracy of determination of hydrogen peroxide by cerate oxidimetry," Analytical Chemistry, vol. 26, no. 2, pp. 320-325, 1954.

[27] L.-S. Zhang and G. T. F. Wong, "Optimal conditions and sample storage for the determination of $\mathrm{H}_{2} \mathrm{O}_{2}$ in marine waters by the scopoletin-horseradish peroxidase fluorometric method," Talanta, vol. 48, no. 5, pp. 1031-1038, 1999.

[28] S. S. Razola, E. Aktas, J.-C. Viré, and J.-M. Kauffmann, "Reagentless enzyme electrode based on phenothiazine mediation of horseradish peroxidase for subnanomolar hydrogen peroxide determination," Analyst, vol. 125, no. 1, pp. 79-85, 2000.

[29] J. Yu and H. Ju, "Amperometric biosensor for hydrogen peroxide based on hemoglobin entrapped in titania sol-gel film," Analytica Chimica Acta, vol. 486, no. 2, pp. 209-216, 2003.

[30] E. Ferapontova and L. Gorton, "Bioelectrocatalytical detection of $\mathrm{H}_{2} \mathrm{O}_{2}$ with different forms of horseradish peroxidase directly adsorbed at polycrystalline silver and gold," Electroanalysis, vol. 15, no. 5-6, pp. 484-491, 2003.

[31] N. Kometani, M. Tsubonishi, T. Fujita, K. Asami, and Y. Yonezawa, "Preparation and optical absorption spectra of dyecoated $\mathrm{Au}, \mathrm{Ag}$, and $\mathrm{Au} / \mathrm{Ag}$ colloidal nanoparticles in aqueous solutions and in alternate assemblies," Langmuir, vol. 17, no. 3, pp. 578-580, 2001.

[32] J. Zhu, Z. Kónya, V. F. Puntes, et al., "Encapsulation of metal (Au, Ag, Pt) nanoparticles into the mesoporous SBA-15 structure," Langmuir, vol. 19, no. 10, pp. 4396-4401, 2003.

[33] F. Gao, Q. Lu, X. Liu, Y. Yan, and D. Zhao, "Controlled synthesis of semiconductor PbS nanocrystals and nanowires inside mesoporous silica SBA-15 phase," Nano Letters, vol. 1, no. 12, pp. 743-748, 2001.

[34] B. D. Cullity, Elements of X-Ray Diffraction, Addison-Wesley, Reading, Mass, USA, 1978.

[35] J.-J. Yu, S. Lu, J.-W. Li, F.-Q. Zhao, and B.-Z. Zeng, "Characterization of gold nanoparticles electrochemically deposited on amine-functioned mesoporous silica films and electrocatalytic oxidation of glucose," Journal of Solid State Electrochemistry, vol. 11, no. 9, pp. 1211-1219, 2007.

[36] A. Burneau, O. Barrès, J. P. Gallas, and J. C. Lavalley, "Comparative study of the surface hydroxyl groups of fumed and precipitated silicas. 2. Characterization by infrared spectroscopy of the interactions with water," Langmuir, vol. 6, no. 8, pp. 1364-1372, 1990.

[37] J. P. Gallas, J. C. Lavalley, A. Burneau, and O. Barres, "Comparative study of the surface hydroxyl groups of fumed and precipitated silicas. 4. Infrared study of dehydroxylation by thermal treatments," Langmuir, vol. 7, no. 6, pp. 12351240, 1991.

[38] E. F. Vansant, P. Der Voort, K. C. Vrancken, et al., Characterization and Chemical Modification of the Silica Surface, Studies in Surface Science and Catalysis, Elsevier Science, Amsterdam, The Netherlands, 1995.
[39] X. Feng, G. E. Fryxell, L.-Q. Wang, A. Y. Kim, J. Liu, and K. M. Kemner, "Functionalized monolayers on ordered mesoporous supports," Science, vol. 276, no. 5314, pp. 923-926, 1997.

[40] Y. Wei, J. Xu, Q. Feng, H. Dong, and M. Lin, "Encapsulation of enzymes in mesoporous host materials via the nonsurfactanttemplated sol-gel process," Materials Letters, vol. 44, no. 1, pp. 6-11, 2000.

[41] S. Besson, T. Gacoin, C. Ricolleau, and J.-P. Boilot, "Silver nanoparticle growth in 3D-hexagonal mesoporous silica films," Chemical Communications, vol. 9, no. 3, pp. 360-361, 2003.

[42] M. Epifani, C. Giannini, L. Tapfer, and L. Vasanelli, "Sol-gel synthesis and characterization of $\mathrm{Ag}$ and $\mathrm{Au}$ nanoparticles in $\mathrm{SiO}_{2}, \mathrm{TiO}_{2}$, and $\mathrm{ZrO}_{2}$ thin films," Journal of the American Ceramic Society, vol. 83, no. 10, pp. 2385-2393, 2000.

[43] A. C. Patel, S. Li, C. Wang, W. Zhang, and Y. Wei, "Electrospinning of porous silica nanofibers containing silver nanoparticles for catalytic applications," Chemistry of Materials, vol. 19, no. 6, pp. 1231-1238, 2007.

[44] C. M. Welch, C. E. Banks, A. O. Simm, and R. G. Compton, "Silver nanoparticle assemblies supported on glassy-carbon electrodes for the electro-analytical detection of hydrogen peroxide," Analytical and Bioanalytical Chemistry, vol. 382, no. 1, pp. 12-21, 2005. 

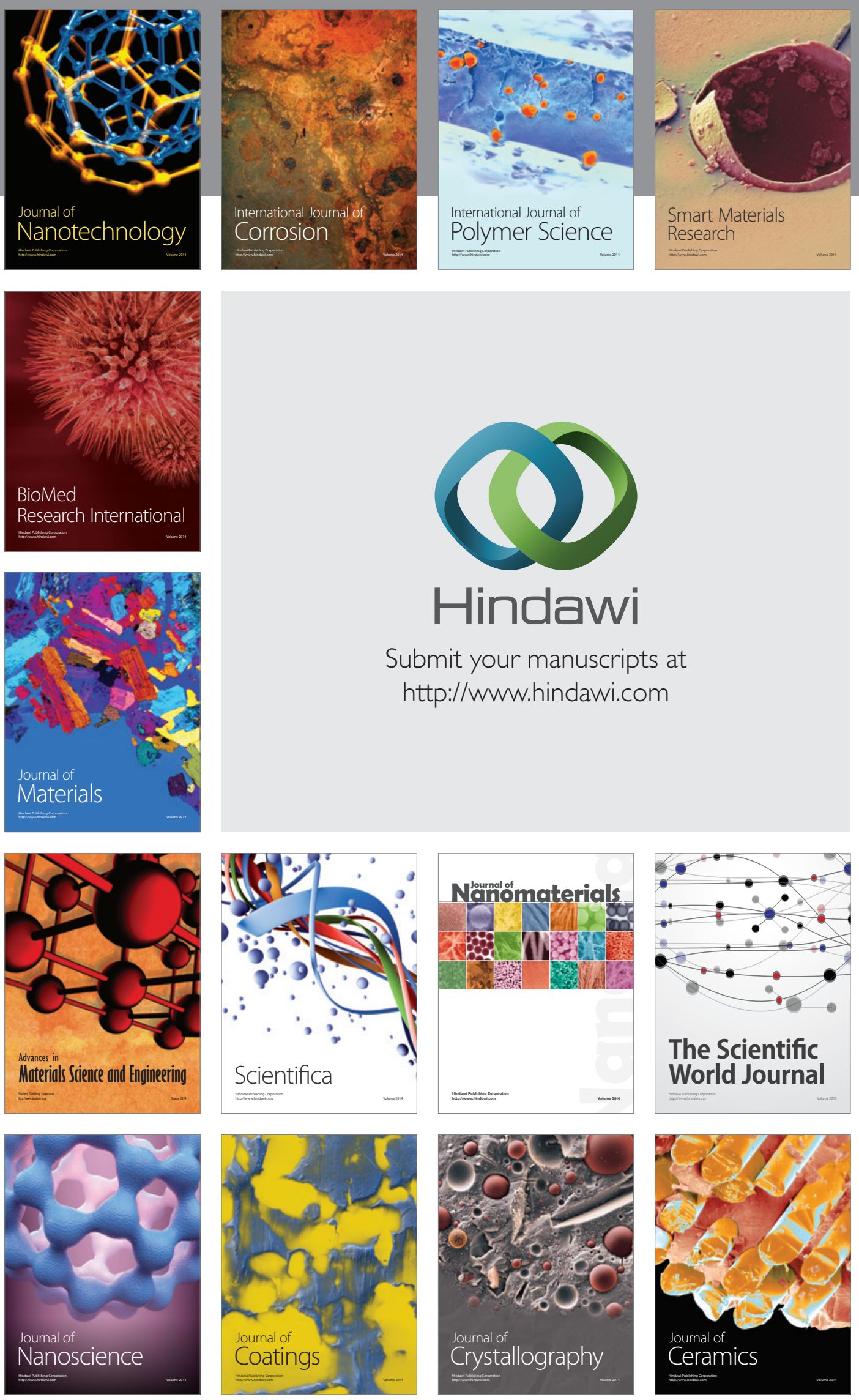

The Scientific World Journal

Submit your manuscripts at

http://www.hindawi.com

\section{World Journal}

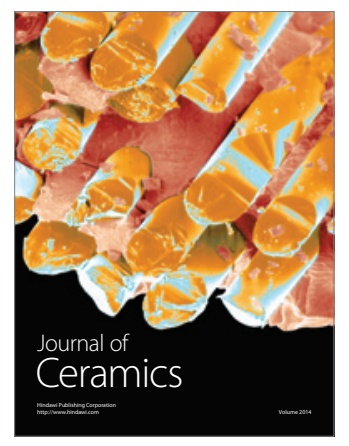

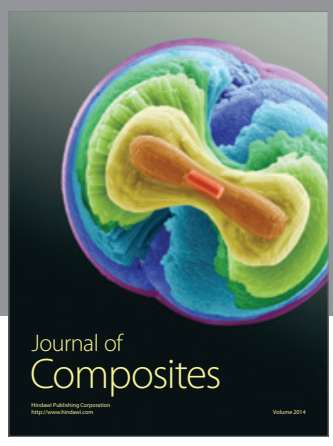
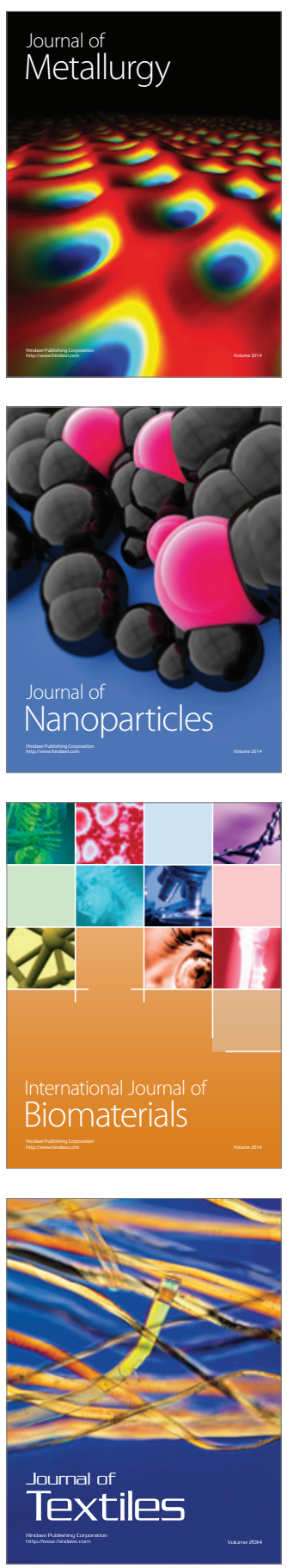